\title{
Morphological and Molecular Confirmation of Parvatrema duboisi Metacercariae in the Manila Clam Ruditapes philippinarum from Gochang-gun, Korea
}

\author{
Taehee Chang', Bong-Kwang Jung1', Hyejoo Shin', Sooji Hong', Jeonggyu Lee', Deok-Gyu Kim', \\ Laddawan Patarwut ${ }^{2}$, Woon-Mok Sohn ${ }^{3}$, Jong-Yil Chai ${ }^{1,4, *}$ \\ 1'Institute of Parasitic Diseases, Korea Association of Health Promotion, Seoul 07649, Korea; ${ }^{2}$ Department of Zoology, Faculty of Science, Kasetsart \\ University, Bangkok, Thailand; ' ${ }^{3}$ nstitute of Health Sciences, Gyeongsang National University College of Medicine, Jinju 52727, Korea; ${ }^{4}$ Department \\ of Tropical Medicine and Parasitology, Seoul National University College of Medicine, Seoul 03080, Korea
}

\begin{abstract}
Gymnophallid metacercariae found in the Manila clam Ruditapes philippinarum ('Banjirak' in Korean) from Gochang-gun, Jeollabuk-do, Korea were morphologically and molecularly confirmed to be Parvatrema duboisi (Dollfus, 1923) Bartoli, 1974. The metacercariae were morphologically characterized by having a large oral sucker, small ventral sucker, genital pore some distance anterior to the ventral sucker, no ventral pit, and 1 compact or slightly lobed vitellarium, which were all compatible with $P$. duboisi. Some of the metacercariae were experimentally fed to mice, and adult flukes were recovered at day 7 post-infection. The morphology of the adult flukes was basically the same as that of the metacercariae except for the presence of uterine eggs; the uterus was filled with up to 40 eggs. The nucleotide sequences (1,193 bp) from ITS regions (ITS1, 5.8S rDNA, and ITS2) of the metacercariae showed $99.7 \%$ identity with $P$. duboisi and $75.7 \%$ identity with Gymnophalloides seoi deposited in GenBank. These results confirmed the presence of $P$. duboisi metacercariae in the Manila clam R. philippinarum in an estuary region of Gochang-gun, Korea.
\end{abstract}

Key words: Parvatrema duboisi, gymnophallid, Manila clam, Gochang-gun, Korea

In gymnophallid trematodes (family Gymnophallidae Odhner, 1905), 5 genera are acknowledged to be valid; Gymnophalloides Fujita, 1925 (syn. Lacunovermis Ching, 1965), Parvatrema Cable, 1953 (syn. Meiogymnophallus Ching, 1965), Gymnophallus Odhner, 1900 (syn. Paragymnophallus Ching, 1973), Pseudogymnophallus Hoberg, 1981, and Bartolius Cremonte, 2001 [1]. The adult flukes generally occur in the intestine, gall-bladder, and bursa Fabricii of marine birds, including shore birds and diving ducks [1]. However, they also occur rarely in mammals, for example, in 2 species of Gymnophalloides; G. seoi in humans and cats [2,3] and $G$. heardi in rats [4].

With regard to Parvatrema, the adult flukes are found exclusively in shore birds and diving ducks [1]. In the Republic of Korea (= Korea), the presence of the life cycle of several gymnophallids have been reported, including G. seoi [2,5], Parva-

- Received 10 September 2019, revised 19 October 2019, accepted 19 October 2019 *Corresponding author (cjy@snu.ac.kr)

(c) 2020, Korean Society for Parasitology and Tropical Medicine

This is an Open Access article distributed under the terms of the Creative Commons Attribution Non-Commercial License (https://creativecommons.org/licenses/by-nc/4.0) which permits unrestricted non-commercial use, distribution, and reproduction in any

medium, provided the original work is properly cited. trema macrostomus n. comb. (syn. Gymnophallus macrostoma Yamaguti, 1939) [6], Parvatrema duboisi (Dollfus, 1923) Bartoli, 1974 (syn. Parvatrema timondavidi Bartoli, 1964) [7], Parvatrema chaii Sohn et al., 2007 [8], Parvatrema homoeotecnum James, 1964 [9], and Parvatrema sinonovaculae n. comb. (Meiogymnophallus sinonovaculae Chai et al., 2007) [10].

In Korea, the presence of $P$. duboisi metacercariae was first documented by $\mathrm{Yu}$ et al. [7]. They detected gymnophallid metacercariae in the Manila clam, Ruditapes philippinarum (syn. Tapes philippinarum), purchased from a fishery market in Seoul and obtained adult flukes after experimental infection to ICR mice. However, the locality of the clam collected was unknown [7]. Subsequently, Sohn et al. [11,12] found metacercariae of Parvatrema spp. (including P. duboisi) in R. philippinarum collected from various areas of Gyeongsangnam-do, Jeollanamdo, and Chungcheongnam-do. In addition, Chung et al. [9] recovered adult flukes of $P$. duboisi from the intestine of great knots Calidris tenuirostris caught from a coastal area of Gunsansi (City), Jeollabuk-do. However, in Gochang-gun, Jeollabukdo, where the Manila clam, R. philippinarum, is abundantly produced, there have been no reports on gymnophallid meta- 

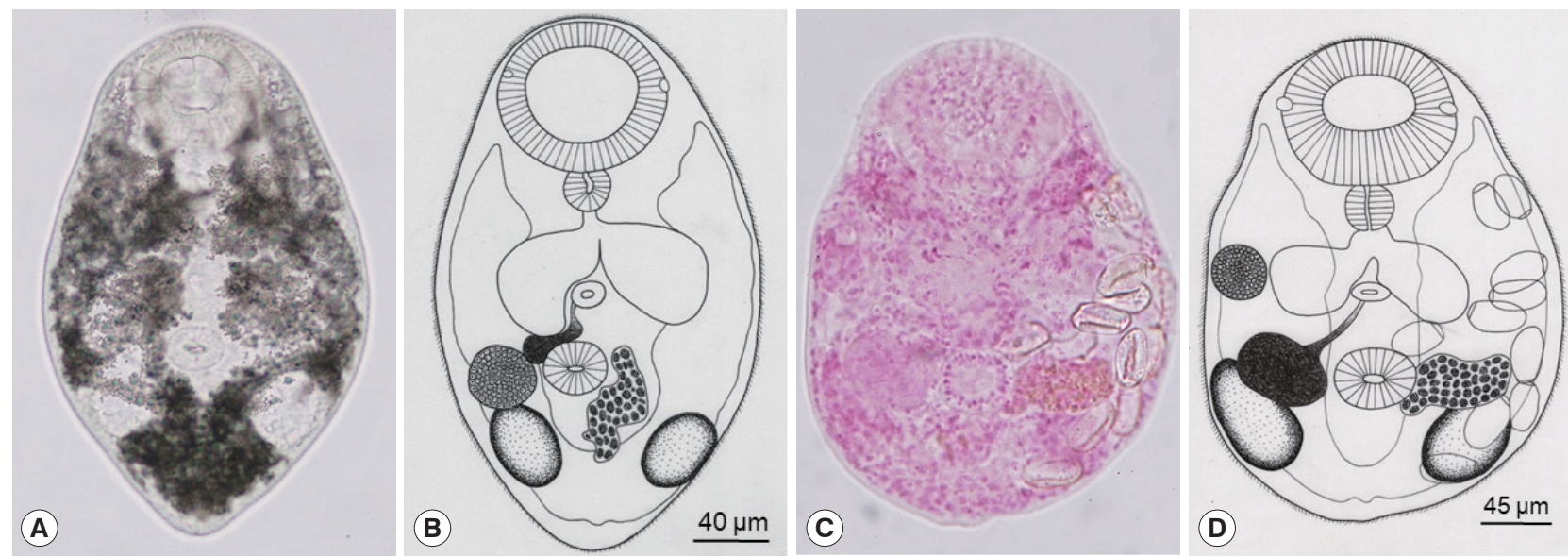

Fig. 1. Parvatrema duboisi metacercariae and adults originating from Gochang-gun, Korea. (A) A living metacercaria isolated from a Manila clam, Ruditapes philippinarum. The oral sucker, ventral sucker, genital pore, and 2 testes are recognizable. (B) Line drawing of the metacercaria showing the internal organs, including the oral sucker, ventral sucker, genital pore, seminal vesicle, ovary, 2 testes, slightly lobed vitellarium, and V-shaped excretory vesicle. (C) An adult fluke recovered from an experimental mouse at day 7 post-infection. The seminal vesicle is well developed and the uterus with eggs is seen. (D) Line drawing of Fig. $1 \mathrm{C}$ showing the oral sucker, ventral sucker, ceca, genital pore, seminal vesicle, ovary, 2 testes, vitellarium, and eggs.

cercariae, including P. duboisi. Thus, the present study was performed to determine the existence of the life cycle of gymnophallid flukes, in particular, P. duboisi, in coastal regions of Gochang-gun, Korea.

The Manila clam, R. philippinarum, was collected from an estuary of Gochang-gun and also purchased from a fishery market in Seoul (those clams having the known origin). The shell of the clam was removed, and the animal was cut into several pieces using a pair of scissors. The animal pieces were incubated at $37^{\circ} \mathrm{C}$ in artificial gastric juice (pepsin- $\mathrm{HCl}$ solution) for 5 min and washed several times with $0.85 \%$ saline. The sediment was examined for gymnophallid metacercariae using a stereomicroscope. Some metacercariae were fixed in $70 \%$ ethanol for molecular studies, and some others were fixed in $10 \%$ formalin for morphological studies.

In order to obtain the adult flukes, laboratory mice (ICR) were experimentally fed the metacercariae isolated from the clam and killed at day 7 post-infection. The animal experiment was performed according to the guidelines of the Committee on the Ethics of Animal Experiments at Seoul National University, Seoul, Korea. The intestines of the mice were resected and examined for the presence of adult flukes. The flukes collected were fixed with $10 \%$ formalin and stained with Semichon's acetocarmine.

Genomic DNA was extracted from metacercariae (8 specimens) using the DNeasy Blood and Tissue kit (Qiagen, Hilden, Germany). The internal transcribed spacer (ITS) re- gions of rDNA, including ITS1, 5.8S rRNA, ITS2, were amplified using the standard PCR protocol with eukaryotic universal primers, $18 \mathrm{~d}\left(5^{\prime}\right.$-cacaccgcccgtcgctactaccgattg- $\left.3^{\prime}\right)$ and $28 \mathrm{cc}\left(5^{\prime}\right.$ -actcgccgttactgagggaatcctggttag- $3^{\prime}$ ) [13]. The amplified product was processed as follows: initial denaturation at $94^{\circ} \mathrm{C}$ for 5 min, 35 cycles of denaturation at $94^{\circ} \mathrm{C}$ for $30 \mathrm{sec}$, annealing at $65^{\circ} \mathrm{C}$ for $30 \mathrm{sec}$, and extension at $72^{\circ} \mathrm{C}$ for $1.3 \mathrm{~min}$, followed by a final elongation at $72^{\circ} \mathrm{C}$ for $5 \mathrm{~min}$. The PCR products were purified and directly sequenced by Macrogen Inc. (Seoul, Korea). The phylogenetic relationships of our sample with other gymnophallid species available in GenBank were analyzed using the maximum-likelihood method.

Based on the morphological (Fig. 1) and molecular data (Fig. 2), the gymnophallid metacercariae found in the Manila clam from Gochang-gun have been confirmed to be P. duboisi. The brief morphologies of the metacercariae and adults of $P$. duboisi were as follows:

The metacercariae $(\mathrm{n}=10)$ were 315 (295-330) $\mu \mathrm{m}$ long and 205 (190-220) $\mu \mathrm{m}$ wide (Fig. 1). The oral sucker was large and well developed with 2 small lateral projections on the lip. The pre-pharynx was absent; the pharynx was round and muscular. The ceca were inflated forming oval sacs. The ventral sucker was small, round in shape, and located posterior to the equatorial line. Two testes were round to elliptical in shape, and located laterally to the ventral sucker. The ovary was in front of the right testis, slightly smaller than the testes. The genital pore was a wide slit-like opening, located some distance anterior to 


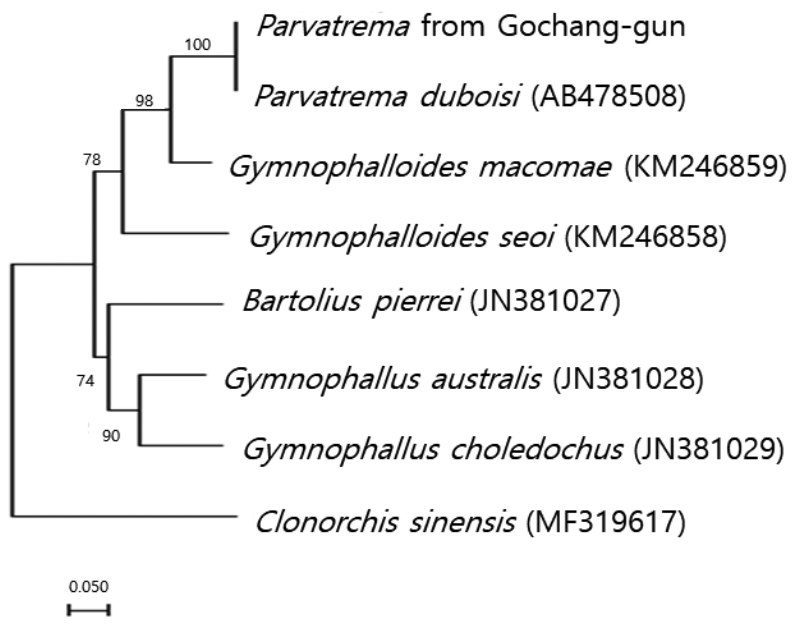

Fig. 2. Phylogenetic tree showing a relationship between Parvatrema from Gochang-gun and members of the family Gymnophallidae available in GenBank analyzed by maximum-likelihood method using Clonorchis sinensis as an outgroup. Bootstrap values of 1,000 replicates are shown on nodes. GenBank accession numbers are indicated for reference species. Scale bar indicates number of nucleotide substitutions per site.

the ventral sucker. The seminal vesicle was unipartite, and connected to the genital pore. The vitellarium was only 1 compact or slightly lobed mass, located nearby the left or postero-sinistral side of the ventral sucker. The excretory bladder was Vshaped with 2 arms reaching to the level of the oral sucker.

The adult flukes $(\mathrm{n}=10)$ were 317 (298-330) $\mu \mathrm{m}$ long and 208 (190-230) $\mu \mathrm{m}$ wide (Fig. 1). The oral sucker was characteristic with 2 small lateral projections on the lip. The pharynx was well developed. The ventral sucker was small, round in shape, and located in the posterior field of the body. Two testes were slightly elliptical in shape, and located laterally to the ventral sucker, vitellarium, and seminal vesicle. The ovary was some distance anterior to the right testis. The genital pore was well developed, located anterior to the ventral sucker. The seminal vesicle was large and unipartite, and connected to the genital pore. The vitellarium was 1 compact or slightly lobed mass, located at postero-sinistral side of the ventral sucker. The excretory bladder was V-shaped with 2 arms reaching to the level of the oral sucker. The uterus was equipped with many loops and a small number of eggs; the egg size was 28 (27-29) $\mu \mathrm{m}$ long and 19 (17-21) $\mu \mathrm{m}$ wide.

The sequences of the ITS region of our specimen revealed only 3 nucleotide substitutions (1,190 of 1,193 sites were identical) from the known sequences of $P$. duboisi deposited in GenBank (no. AB478508). The sequence identity was 99.7\%.
Meanwhile, our sample showed a sequence homology of only $75.7 \%$ in comparison with G. seoi. The phylogenetic tree (Fig. 2) showed that our sample was genetically closest to $P$. duboisi and quite close to Gymnophalloides macomae n. comb. Scholz, 2002 [syn. Lacunovermis macomae (Lebour, 1908) Loos-Frank, 1970] and G. seoi, but far from Bartolius pierrei, Gymnophallus australis, and G. choledochus.

The taxonomy of gymnophallid flukes has been highly complex and confusing. Ching [14] created 2 new genera, $L a-$ cunovermis (wide genital pore, ventral pit present) and Meiogymnophallus (small genital pore, no ventral pit). However, Yamaguti [15] and Scholz [1] synonymized Lacunovermis with Gymnophalloides (small genital pore, ventral pit present), both having a ventral pit, but because the size of the genital pore could not be a significant character to differentiate the 2 genera. Scholz [1] also synonymized Meiogymnophallus with Parvatrema because the difference between the 2 genera given by Ching $[14,16]$ was only the size of the genital pore, small in the former and wide in the latter. Ching [17] also created a new genus Paragymnophallus to accept those gymnophallids having a wide genital pore situated at a distance anterior to the ventral sucker. However, this genus was synonymized with Gymnophallus by Scholz [1].

Therefore, currently in the genus Parvatrema, about 24 species are included; P. affinis Jameson and Nicoll, 1913, P. borealis Stunkard and Uzmann, 1958, P. borinqueñae Cable, 1953, P. bushi Ching, 1995, P. chaii Sohn et al., 2007, P. donacis Hopkinds, 1958, P. duboisi (Dollfus, 1923), P. fossarum Bartoli, 1965, P. homoeotecnum James, 1964, P. isostoma Belopolskaja, 1966, P. jamesoni (Bowers, 1965), P. lintoni (Linton, 1928), P. macrostomus (Yamaguti, 1939), P. margaritense (Ching, 1982), P. minutus (Cobbold, 1859), P. obscurum Ching, 1960; P. ovoplenum (James and Nicoll, 1913), P. polymesoda Ching, 1995, P. rebecqui Bartoli, 1983, P. rebunense Shimazu, 1975, P. sinonovaculae Chai et al., 2007, P. skrjabini Ryschikov, 1963, P. somateriae (Levinsen, 1881), and P. strigatus Lebour, 1908 [1,18].

Our specimens (P. duboisi) from Gochang-gun, Korea had only 1 compact or slightly lobed vitellarium. Thus, they differed from P. affinis, P. fossarum P. jamesoni, P. macrostomus, $P$. minutus, P. obscurum, P. rebecqui, P. sinonovaculae, P. skrjabini, $P$. somateriae, and $P$. strigatus which have a paired group of vitellaria and previously assigned to Meiogymnophallus $[14,18]$. Among the others, 7 species, including P. borinqueñae, P. bushi, P. chaii, P. donacis, P. duboisi, P. polymesoda, and P. rebunense, have a single compact vitellarium and were comparable with 
our specimens. Their differential points from our specimens were as follows. P. borinqueñe is characterized by its small egg size $(12-19 \mu \mathrm{m}$ long) and the presence of gland cells around the oral sucker [4]. P. bushi has a small delicate body with fewer body spines, smaller lateral papillae, smaller pharynx, and shallower genital atrium [4]. P. chaii is characterized by smaller-sized eggs (18-20 $\mu \mathrm{m}$ long), the presence of an anterior arch of 16-17 sensory papillae on the genital pore, and club-shaped seminal vesicle [8]. P. donacis is distinct having a large body size and does not have an esophagus [19], whereas our specimens have a smaller body and a short esophagus. P. polymeso$d a$ is characterized by a large body size, large lateral papillae, large ceca, but a small vitellarium [4]. P. rebunense differs from our samples in the shape of its ovary which is slightly lobed and elongated oval [20]. Based on these differential points, our specimens could be assigned as P. duboisi.

The morphological diagnosis of our samples was supported by the results of sequencing of the ITS region. The homology with P. duboisi was 99.7\%, while the homology with G. seoi was $75.7 \%$. In GenBank, there are nucleotide data of only 2 Parvatrema sp., P. duboisi and Parvatrema sp., so that comparison of our specimens with other species of Parvatrema could not be done.

In 1923, Dollfus [21] described Gymnophallus duboisi with the metacercariae obtained from the marine mussel Mytilus galloprovincialis in France. In 1963, Bartoli [22] described a new species of Parvatrema (P. timondavidi) based on metacercariae from M. galloprovincialis collected from the Gulf of Marseille, France. However, in 1974, Bartoli [23] found that the worm described by him in 1963 was identical with those of Gymnophallus duboisi and named it as Parvatrema duboisi synonymizing P. timondavidi with P. duboisi. Separately from this, in 1944, Ogata [24] obtained gymnophallid metacercariae from a bivalve Ruditapes philippinarum in Japan and adults from an experimental rat and described them as Gymnophallus bursicola which was originally reported by Odhner in 1900. Endo and Hoshino [25] in 1974 found that these metacercariae and adults were different from G. bursicola and should be assigned to P. timondavidi. In 1982, Shimura et al. [26] detected the same metacercariae from $R$. philippinarum in the Lake Hamana and determined them as $P$. duboisi. Later, Yanagida et al. [13] discovered the larval stages of this gymnophallid, including the sporocyst containing cercariae and free metacercariae in the Manila clam in Ariake Sea, Japan and obtained adult flukes in experimental mice and rats.
In conclusion, the present study confirmed the presence of the life cycle of $P$. duboisi in an estuary area of Gochang-gun using the Manila clam R. philippinarum as (the first and) the second intermediate host. The possibility of human infection with this gymnophallid should be ruled out in Korea where people like to consume the Manila clams.

\section{ACKNOWLEDGMENT}

We thank the staff of Institute of Parasitic Diseases, Korea Association of Health Promotion who helped this study.

\section{CONFLICT OF INTEREST}

We have no conflict of interest related to this work.

\section{REFERENCES}

1. Scholz T. Family Gymnophallidae odhner, 1905. In Gibson DI, Jones A, Bray RA eds. Keys to the Trematoda. Vol. 1. London, UK. Natural History Museum. 2002, pp 245-251.

2. Chai JY, Choi MH, Yu JR, Lee SH. Gymnophalloides seoi: a new human intestinal trematode. Trends Parasitol 2003; 19: 109-112.

3. Shin EH, Park JH, Guk SM, Kim JL, Chai JY. Intestinal helminth infections in feral cats and a raccoon dog on Aphae Island, Shinan-gun, with a special note on Gymnophalloides seoi infection in cats. Korean J Parasitol 2009; 47: 189-191.

4. Ching HL. Four new species of gymnophallid digeneans from rice rats, willets, and molluscs in Florida. J Parasitol 1995; 81: 924-928

5. Lee SH, Chai JY, Hong ST. Gymnophalloides seoi n. sp. (Digenea: Gymnophallidae), the first report of human infection by a gymnophallid. J Parasitol 1993; 79: 677-680.

6. Yamaguti S. Studies on the helminth fauna of Japan. Part 25. Trematodes of birds IV. Jpn J Zool 1939; 8: 129-210.

7. Yu JR, Chai JY, Lee SH. Parvatrema timondavidi (Digenea: Gymnophallidae) transmitted by a clam, Tapes philippinarum, in Korea. Korean J Parasitol 1993; 31: 7-12.

8. Sohn WM, Na BK, Ryang YS, Ching H, Lee SH. Parvatrema chaii n. sp. (Digenea: Gymnophallidae) from mice experimentally infected with metacercariae collected from surf-clam, Mactra veneriformis. Korean J Parasitol 2007; 45: 115-120.

9. Chung OS, Lee HJ, Sohn WM, Park YK, Chai JY, Seo M. Discovery of Parvatrema duboisi and Parvatrema homoeotecnum (Digenea: Gymnophallidae) from migratory birds in Korea. Korean J Parasitol 2010; 48: 271-274.

10. Chai JY, Han ET, Choi D, Seo M, Kim JL, Guk SM, Shin EH, Lee $\mathrm{SH}$. A new gymnophallid trematode from the intestine of mice infected with metacercariae from the razor clam Sinonovacula constricta. J Parasitol 2007; 93: 132-137. 
11. Sohn WM, Chai JY, Lee SH. Infection status of Tapes philippinarum collected from southern coastal areas of Korea with Parvatrema spp. (Digenea: Gymnophallidae) metacercariae. Korean J Parasitol 1996; 34: 273-277 (in Korean).

12. Sohn WM, Na BK, Cho SH, Lee WJ. Prevalence and density of digenetic trematode metacercariae in clams and oysters from western coastal regions of the Republic of Korea. Korean J Parasitol 2017; 55: 399-408.

13. Yanagida T, Shirakashi S, Iwaki T, Ikushima N, Ogawa K. Gymnophallid digenean Parvatrema duboisi uses Manila clam as the first and second intermediate host. Parasitol Int 2009; 58: 308310.

14. Ching HL. Life cycles of Lacunovermis conspicuus n. gen., n. sp. and Meiogymnophallus multigemmulus n. gen., n. sp. (Gymnophallidae: Trematoda) from Macoma inconspicua and diving ducks from Vancouver, Canada. Proc Helminthol Soc Wash 1965; 32: 53-63.

15. Yamaguti S. Synopsis of Digenetic Trematodes of Vertebrates. Vol. I. Tokyo, Japan. Keigaku Publishing Co. 1971, pp 511-515.

16. Ching HL. Evaluation of characters of the digenean family Gymnophallidae Morozov. 1955. Can J Fish Aquat Sci 1995; 52 (suppl): 78-83.

17. Ching HL. Paragymnophallus odhneri gen.n., sp. n. (Trematoda: Gymnophallidae) for Gymnophallus somateriae sensu Odhner (1900, 1905). Can J Zool 1973; 51: 807-810.

18. Cremonte F, Gilardoni C, Pina S, Rodrigues P, Ituarte C. Revision of the family Gymnophallidae Odhner, 1905 (Digenea) based on morphological and molecular data. Parasitol Int 2015; 64: 202-210.
19. Bartoli P. Données novelles sur la morphologie et la biologie de Parvatrema timondavidi Bartoli 1963 (Trematoda: Digenea). Ann Parasitol (Paris) 1965; 40: 155-164 (in French).

20. Shimazu T. On Parvatrema rebunense sp. nov. (Trematoda: Digenea: Gymnophallidae). Jpn J Parasitol 1975; 24: 300-311 (in Japanese).

21. Dollfus RP. Le Trématode des perles de nacre des moules de Provence. C R Acad Sci Paris 1923; 176: 1427-1429 (in French).

22. Bartoli P. Note preliminaire sur l'anatomie et la biologie de Parvatrema timondavidi n. sp. (Trematoda: Digenea). C R Acad Sci Paris 1963; 273: 518-520 (in French).

23. Bartoli P. Researches sur le Gymnophallidae F. N. Morozov, 1955 (Digenea), parasites d'oiseaux des côtes de Camargue: systématique, biologie et ecologie. [master's thesis]. [Marseille]: Université de Droit, d'Economie et des Sciences d'Aix-Marseille; 1974, pp 1-338.

24. Ogata T. On the morphology, ecology and life history of an agamodistome parasitic in a bivalve, Paphia (Ruditapes) philippinarum (Adames et Reeve). Sci Rep Tokyo Bunrika Daigaku 1944; 7: 1-24.

25. Endo T, Hoshina T. Redescription and identification of a gymnophallid trematode in a brackish water clam, Tapes (Ruditapes) philippinarum. Jpn J Parasitol 1974; 23: 73-77.

26. Shimura S, Yoshinaga T, Wakabayashi H. Two species of marine metacercariae, Parvatrema duboisi (Gymnophallidae) and Proctoeces sp. (Fellodistomidae), in the clam Tapes philippinarum from Lake Hamana, Japan: morphology and level of infection. Fish Pathol (Japan) 1982; 17: 187-194 (in Japanese). 
